\title{
Wind turbines in icing conditions: performance and prediction
}

\author{
S. Dierer ${ }^{1}$, R. Oechslin ${ }^{1, *}$, and R. Cattin ${ }^{1}$ \\ ${ }^{1}$ Meteotest, Fabrikstrasse 14, 3012 Bern, Switzerland \\ * formerly at: University of Innsbruck, Innrain 52, 6020 Innsbruck, Austria
}

Received: 5 January 2011 - Revised: 1 April 2011 - Accepted: 8 April 2011 - Published: 6 September 2011

\begin{abstract}
Icing on structures is an important issue for wind energy developments in many regions of the world. Unfortunately, information about icing conditions is mostly rare due to a lack of measurements. Additionally, there is not much known about the operation of wind turbines in icing conditions. It is the aim of the current study to investigate the effect of icing on power production and to evaluate the potential of icing forecasts to help optimizing wind turbine operation.

A test site with two Enercon E-82 turbines was set up in the Jura region in Switzerland in order to study the turbines' behaviour in icing conditions. Icing forecasts were performed by using an accretion model driven by results of the mesoscale weather forecast model WRF.

The icing frequency at the test site is determined from pictures of a camera looking at the measurement sensors on the nacelle. The results show that the site is affected by frequent icing: 11.5 days/year of meteorological icing and 41.5 days/year of instrumental icing were observed corresponding to a factor of about four. The comparison of power production with and without blade heating shows that blade heating results in a $3.5 \%$ loss and operation without blade heating results in a $10 \%$ loss of the annual power production due to icing. Icing forecasts are performed for winter 2009/2010. Simulated and observed icing events agree well and also coincide with periods of power drop. Thus, the results suggest that icing forecasts can help to optimize the operation of wind parks in icing conditions.
\end{abstract}

\section{Introduction}

Icing on structures affects wind energy developments in many regions of the world. Icing causes loss of power production (Jasinski et al., 1998; Wang et al., 2007), risk of ice throw (Seifert et al., 2003), turbine fatigue due to additional loads and possible imbalances (Frohboese and Anders, 2007) and increased noise. Knowing the icing effects helps during the planning phase of a wind energy development as well as during operation. Still, the knowledge of icing risk is limited for most regions in the world since operational icing measurements are rare. Additionally, there is not much known about wind turbine operation in icing conditions.

The knowledge about the operation of real wind farms in icing conditions is little. Westerhellweg and Mönnich (2010) compared the operation of wind farms in icing conditions in

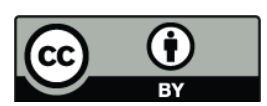

Correspondence to: S. Dierer

(silke.dierer@meteotest.ch)
France, Austria, Canada and Switzerland. They found significant differences in power loss depending on the icing conditions as well as on the operation of the wind farms (heated or non-heated, stop in case of icing or continued operation). Several studies show that the effect of icing on wind turbine operation not just depends on the kind of icing (Hochart et al., 2008) but also on the turbine itself (Jasinski et al., 1998; Homola et al., 2010). The equipment of the turbine with an anti- or de-icing system is of major importance. Anti-icing methods aim at preventing ice accretion (e.g. hydrophobic coating) while de-icing methods aim at effectively removing accreted ice (e.g. heating). The most tested and reliable way to prevent icing effects is active heating of blades (Parent and Ilinca, 2011). The method of detecting icing on the blades affects the efficiency of the de-icing system (Homola et al., 2006; Parent and Ilinca, 2011). An anti-icing method to prevent or reduce icing on blades is icephobic coatings (Karmouch et al., 2009). 


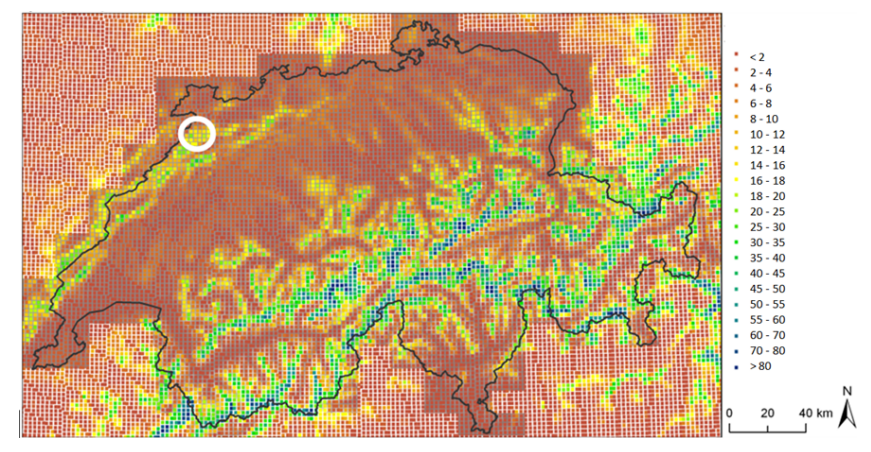

Figure 1. Map of icing frequency [days/year] in Switzerland in $100 \mathrm{~m}$ height. The position of St. Brais is marked by a white circle.

The current study aims at investigating the effect of a blade heating system for an Enercon E-82 turbine installed in Switzerland. A Swiss project was setup with the overall goal to study wind turbines in operation in icing conditions. The investigations are performed at the test site St. Brais in the Swiss Jura, where two Enercon E-82 turbines were installed in September 2009. Studies focus on icing frequency and intensity at St. Brais, efficiency and reliability of the rotor blade heating system and production losses due to icing with and without blade heating. First results are presented in this paper.

Icing on blades can cause sudden decreases of power production, so-called ramps, that might affect grid stability. Being able to predict icing events would be valuable for the operation of power lines, cable cars or measurement stations in icing conditions and would also help to optimize wind energy operation by allowing to predict downtimes due to icing. Still, icing on structures is difficult to predict and, thus, it needs to be clarified if the quality of forecasts is good enough to be applied for operation planning. Weather forecast models made a strong development in the recent years allowing increased resolution due to grown computing resources and using improved cloud microphysics parameterizations. In the current study, icing forecasts are calculated based on results of the weather research and forecasting model WRF (Skamrock et al., 2008) driving an accretion model (Makkonen, 2000). Icing simulations show a time dependent, threedimensional picture of icing conditions. Icing forecasts for the turbines at St. Brais are compared to observed ice cover. The results for winter 2009/2010 are presented.

The test site St. Brais is described in Sect. 2. The turbine operation with and without blade heating system during winter 2009/2010 is described in Sect. 3. In Sect. 4 the forecasting system and the comparison of forecasted and observed icing for winter 2009/2010 are described. Results are summarized in Sect. 5.

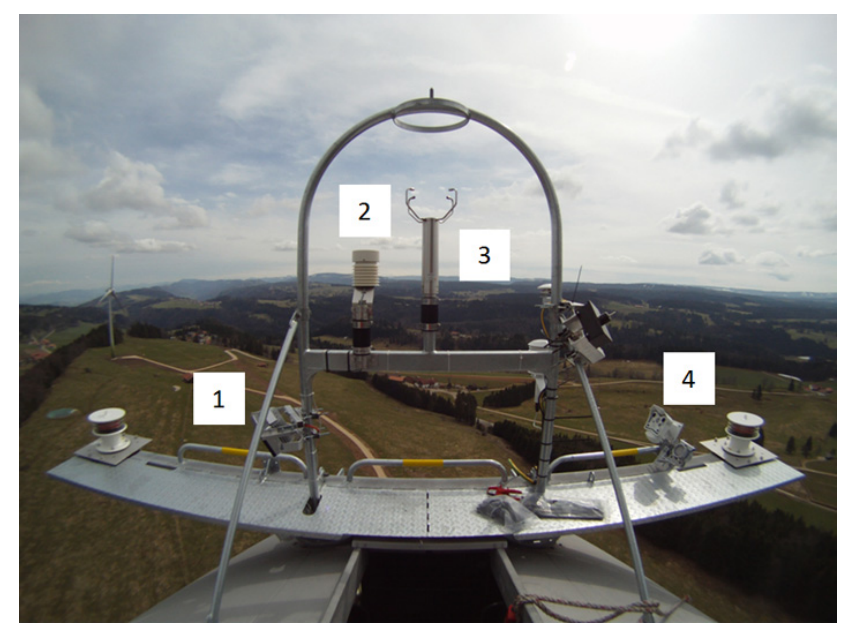

Figure 2. Measurement instruments on the turbine at St. Brais: a camera looking at the blades (1), a temperature and humidity sensor (2), a nacelle anemometer (3) and a camera looking at the sensors (4).

\section{Test site St. Brais}

The test site St. Brais is situated in the complex terrain of the Swiss Jura, in the northern part of Switzerland (Fig. 1). It is a region of frequent icing. According to the icing map of Switzerland (Dierer et al., 2010) a meteorological icing frequency of around 14-16 days per year is expected at $100 \mathrm{~m}$ height (Fig. 1).

The test site St. Brais consists of two Enercon E-82 wind turbines with a hub height of $78 \mathrm{~m}$. The turbines are equipped with an ice detection system (based on the comparison of the current power output to the turbine specific power curve) and a rotor blade heating system for de-icing. The nacelle is equipped with sensors measuring wind, temperature and relative humidity (Fig. 2, additional sensors measuring radiation and icing are installed in March 2010). Two webcams are monitoring the rotor blades and the nacelle anemometer (Fig. 2). The camera pictures are used for a manual classification of icing conditions.

\section{Wind turbine operation in icing conditions}

Icing on structures takes place in different stages: during the period of meteorological icing, meteorological conditions favor ice formation, but the surface of the structure might prevent ice growth (e.g. surface too warm). The instrumental icing describes the period when the measurement instrument or the wind turbine is affected by icing. This means that ice accretion exists at the instrument or wind turbine and disturbs its operation. A sketch of the different stages is shown in Fig. 3. 


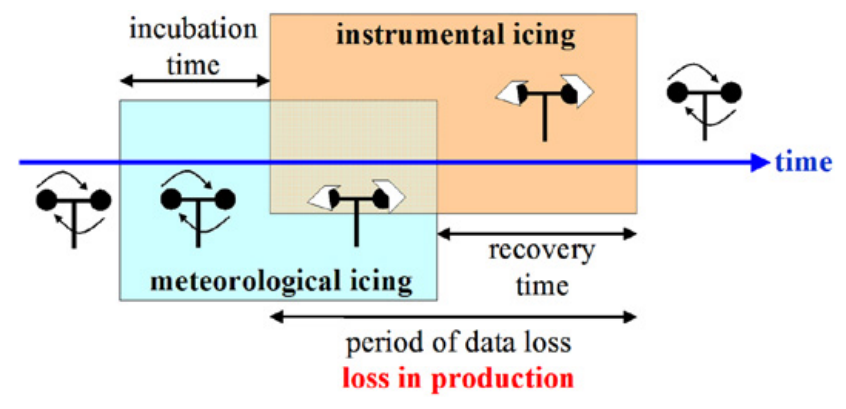

Figure 3. Sketch of periods with meteorological and instrumental icing.

The frequency of icing was investigated based on the pictures of the nacelle camera looking at the measurement sensors (Fig. 2). Twelve icing events occurred during November 2009 and March 2010 with a total length of 11.5 days of meteorological icing. The longest event of meteorological icing lasted 2.6 days. The period of instrumental icing had a total length of 41.5 days, with the longest period lasting about 10 days. Thus, the ratio between instrumental and meteorological icing is about four at the investigated site.

Both E-82 wind turbines are equipped with blade heating. The turbines are stopped if ice is detected. The blades are heated for $3 \mathrm{~h}$ and the turbine is restarted automatically. Two operation modes, with and without blade heating, are compared. If no blade heating is applied, the turbine is stopped when a power drop indicates the existence of icing and the turbine is restarted automatically if the temperature was above $2{ }^{\circ} \mathrm{C}$ for six hours. The power loss with and without blade heating is compared.

Being operated with blade heating the downtime reduced to the periods of meteorological icing (Fig. 4). The production loss due to downtimes was $3 \%$ of the annual power production. Additionally, the power consumption for the heating of the blades corresponded to about $0.5 \%$ of the annual power production resulting in a total loss of $3.5 \%$ due to icing. If the turbine would have been operated without blade heating the downtime would be prolongated to 56 days during winter 2009/2010. The downtime corresponds to a loss of $10 \%$ of the annual power production, thus, a loss of $6.5 \%$ of the annual power production compared to using blade heating. The factor of the length of the downtime without and with blade heating is 4.8 .

This result is checked during a test period in January 2010 when the blade heating was turned off at one of the turbines. During the month-long test period the turbine without blade heating lost about $2.5 \%$ of the annual power production compared to the turbine using blade heating. This values is in the range of the average energy loss of $1.6 \%$ per month that was estimated based on calculated downtimes. In Summary, the results show that blade heating significantly increases the power production in regions that are frequently affected by icing.

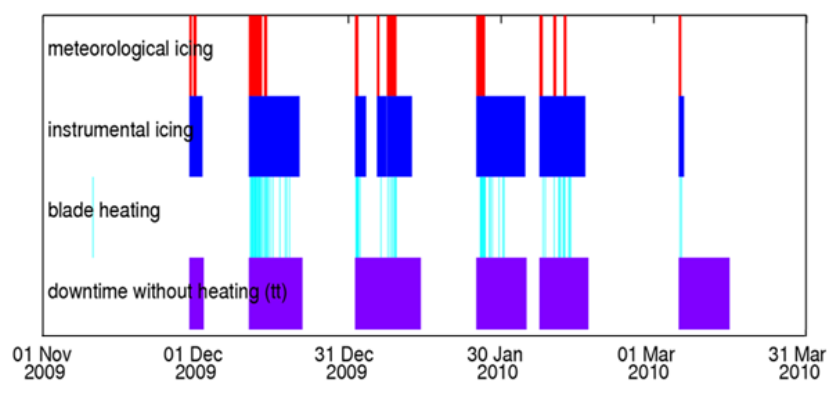

Figure 4. Periods of meteorological (first row) and instrumental icing, downtimes due to blade heating and downtimes without blade heating at St. Brais during winter 2009/2010.

\section{Forecasts of icing}

Icing forecasts are a possible tool to optimize the operation of wind turbines under icing conditions. They could help to improve power forecasts by considering downtimes due to icing. Icing forecasts based on numerical weather prediction models have been out of reach before increased computing power allowed high model resolutions and microphysical schemes gained precision. It is just until recently that the precision of numerical weather models allows testing their ability in this field.

In the current study, icing simulations are based on results of the weather research and forecasting (WRF) model coupled to an icing algorithm (Makkonen, 2000). WRF is a state-of-the-art non-hydrostatic numerical model for high resolution weather forecasts (Skamarock et al., 2008). It is developed for research purposes as well as for operational weather forecasts. Three nested model domains with grid sizes of $12 \mathrm{~km}, 4 \mathrm{~km}$ and $1.3 \mathrm{~km}$ are used. Initial and boundary conditions are derived from GFS $0.5^{\circ}$ forecast data. The forecast length is $60 \mathrm{~h}$ and icing forecasts are calculated for the forecast horizon between 12 and $36 \mathrm{~h}$. The simulations for the current study are performed with WRF ARW version 3.1. Turbulence is calculated with the Mellor Yamada scheme and the surface layer is parameterized using a Monin-Obukov scheme. The land surface is calculated with the unified Noah land surface scheme. No cumulus convection parameterization is applied. Cloud microphysics is parameterized by a sophisticated cloud microphysics scheme by Thompson et al. (2004, 2008) allowing a good description of humidity, liquid and frozen water components. The scheme includes a two moment (mass and number concentration) description for cloud ice and rain, which is considered to be important for the prediction of supercooled water in the atmosphere. Radiation is simulated using the RRTM longwave radiation scheme and the Dudhia shortwave radiation scheme. 


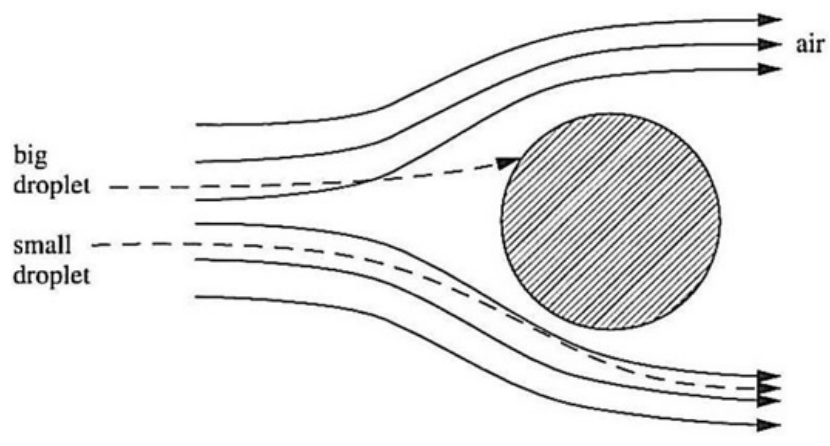

Figure 5. Sketch of the accretion model by Makkonen (2000): droplet flow around a cylinder (taken from Makkonen, 2000).

An accretion model (Makkonen, 2000) is used to describe the ice accretion on a freely rotating cylindrical structure by in-cloud icing. Beside cloud droplets also freezing drizzle is taken into consideration. Freezing drizzle is not very frequent, but it gives a strong contribution to the ice load if it occurs. The ice load accumulating on a cylindrical structure is simulated by using information about temperature, liquid water content (LWC) and wind speed, taken from the weather model WRF, as well as the volume number concentration of droplets. The latter is used to calculate the median volume droplet size (MVD) and needs to be estimated based on measurements or climatological values. The accretion model calculates the liquid water mass flux that hits the cylindrical structure and the part of liquid water that contributes to icing (Fig. 5) described by several coefficients:

- Collision efficiency: ratio of droplets that actually hits the object. Reduced because small particles are transported around the obstacle due to their small inertia.

- Sticking efficiency: ratio of droplets that hit the object that is collected, reduced because some particles bounce off from the surface.

- Accretion efficiency: part of collected droplets that contributes to the rate of icing, reduced if the heat flux is too small to cause sufficient freezing.

Icing forecasts are calculated for the period from November 2009 to March 2010 and compared to the icing derived from the nacelle camera. Five categories of icing intensity are introduced and the hourly pictures are classified accordingly. The result is shown as grey shading in Fig. 6 together with the simulated ice load (shown in red). Additionally, the difference between the real and the theoretical power production calculated from wind measurements and power curve is given in green. If the theoretical power production gets higher than the real one, it is an indicator for a power drop due to icing. The comparison of observed icing periods and periods with reduced power production shows a very good agreement. During all icing periods, the influence of icing
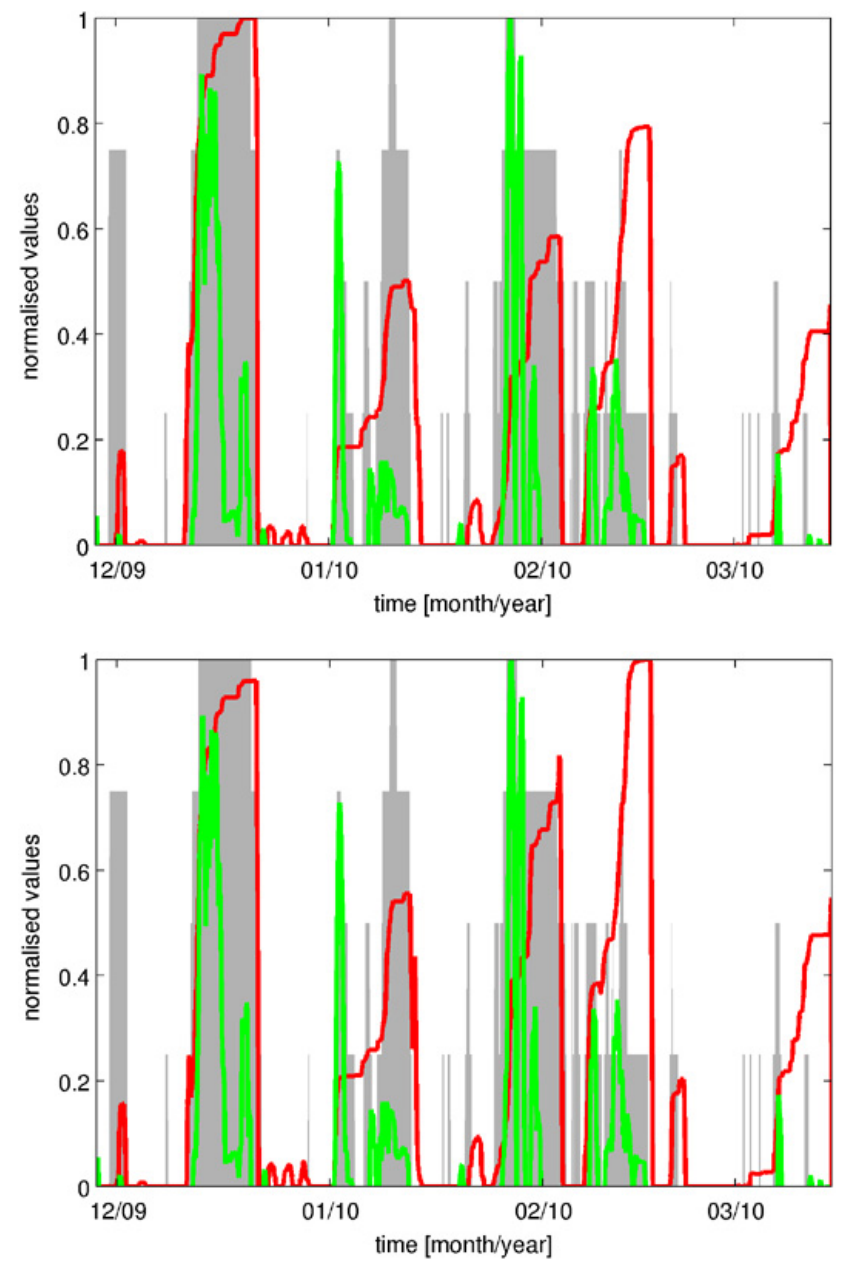

Figure 6. Time series of ice cover at the nacelle based on camera pictures (grey shading), simulated ice load at $1.3 \mathrm{~km}$ (upper panel) and $4 \mathrm{~km}$ respectively (lower panel) grid size (red line) and difference between theoretical and real power production (green line). The grey shading indicates five ice load classes derived from subjective classification based on pictures of the nacelle camera. The higher the column, the higher the ice load.

was significant enough to cause a power drop. The relation between accreted ice mass and power drop strongly depends on the turbine and the way of operation and needs further investigation.

The comparison of observed and simulated ice load shows a good agreement. All bigger icing events are captured by the model. There is just one icing event simulated by the model when just weak icing happened in reality. The simulated start of the icing periods agrees very well with the observed one. The simulation slightly overestimates the length of the icing periods. The reason is that melting occurs in the model just due to positive heat fluxes. Radiation is not considered and wind effects are considered in a basic way. Thus, important mechanisms for reducing the ice cover are missing. 
Additionally, the icing algorithm assumes a cylindrical structure of the ice cover which seldom occurs in reality and, thus, e.g. wind effects are underestimated. The simulated ice mass could not be evaluated due to missing quantitative observation data regarding ice mass. In summary, the occurrence of icing is simulated well and also agrees with the periods when power production is reduced compared to its theoretical value.

A sensitivity study using $4 \mathrm{~km}$ grid size instead of $1.3 \mathrm{~km}$ grid size shows very similar results for the icing forecasts. There are slight changes of the simulated ice mass, but start and end of the icing events remain nearly unchanged. This indicates that in moderately complex terrain like in the Swiss Jura, grid sizes around $3 \mathrm{~km}$ might be sufficient in order to simulate the occurrence of icing.

\section{Summary and conclusions}

The test site St. Brais in the Swiss Jura was set up in order to study the operation of wind turbines in icing conditions. First results are derived from observations during November 2009 and March 2010. The icing frequency is determined manually from pictures of the nacelle camera showing a frequency of meteorological icing of 11.5 days/year. The frequency of instrumental icing is 41.5 days/year resulting in a ratio of about four between instrumental and meteorological icing. This gives a first indication about the little known factor for the Alpine region. It differs significantly depending on the region in terms of geographical latitude, height, solar irradiance, temperature conditions etc. The factor is of interest because normally information either on meteorological or instrumental icing is available.

The comparison of power production with and without blade heating reveals significant differences. If blade heating is applied, the power loss due to downtimes because of icing is about $3.0 \%$ and the power demand of the blade heating system is $0.5 \%$ resulting in a total power loss of $3.5 \%$ due to icing. Without blade heating about $10 \%$ of the annual power production are lost due to icing. This result is confirmed during a test period in January 2010. The study shows that the blade heating system works reliable and that it prevents a remarkable part of the power loss. An alternative version of blade heating, whereby blade heating is possible during power production of the turbine, is planned to be investigated beginning of 2011.

Icing forecasts are performed using the weather forecast model WRF coupled to an icing algorithm developed by Makkonen (2000). Forecasts were performed for the winter period 2009/2010 and simulated icing was compared with observed icing derived from camera pictures. There is a good agreement between simulated and observed icing events and also with periods of power drop. There is a slight tendency to overestimate the duration of icing events because not all necessary processes for ice reduction are included in the model.
Further work is needed to improve the consideration of wind and radiation effects. The results suggest that icing forecasts are a suitable tool to optimize the operation of wind parks in icing conditions. The next step will be a combination of icing and power forecasts.

Acknowledgements. The authors wish to thank the Federal Office of Energy (Switzerland) for funding this project, Enercon $\mathrm{GmbH}$ for the technical and financial support, the operator ADEV Windkraft AG for making the wind turbines accessible for this project and the University of Innsbruck for providing computing resources for the WRF simulations. Additionally, the authors thank the reviewers A. Westerhellweg and another anonymous referee for their constructive comments that helped to improve the paper.

Edited by: E. Batchvarova

Reviewed by: A. Westerhellweg and another anonymous referee

\section{SC 1 The publication of this article is sponsored by the Swiss Academy of Sciences.}

\section{References}

Dierer, S., Cattin, R., Steiner, P., Grünewald, T., Steinkogler, W., and Lehning, M.: Vereisungskarte der Schweiz, Final report of the project funded by the Federal Office of Energy, http://www.bfe.admin.ch/php/modules/enet/streamfile. php?file $=000000010509$.pdf \&name $=000000290299,2010$.

Frohboese, P. and Anders, A.: Effects of Icing on Wind Turbine Fatigue Loads, The Science of Making Torque from Wind, J. Physics, Conference Series, 75, 012061, doi:10.1088/17426596/75/1/012061, 2007.

Hochart, C., Fortin, G., Perron, J., and Ilinica, A.: Wind turbine performance under icing conditions, Wind Energy, 11, 319-333, 2008.

Homola, M. C., Nicklasson P. J., and Sundsbø, P. A.: Ice sensors for wind turbines, Journal of Cold Regions Science and Technology, 46, 125-131, 2006.

Homola, M. C., Wallenius, T., Makkonen, L., Nicklasson, P. J., and Sundsbo, P. A.: The relationship between chord length and rime icing on wind turbines, Wind Energy, 13, 627-632, 2010.

Jasinski, W. J., Noe, S. C., Selig, M. S., and Bragg, M. B.: Wind turbine performance under icing conditions, J. Sol. Energy Eng., 120, 60-65, 1998.

Karmouch, R., Coude, S., Abel, S., and Ross, G. G.: Icephobic PTFE coatings for wind turbines operating in cold climate conditions, Electrical Power \& Energy Conference (EPEC), 2009 IEEE, doi:10.1109/EPEC.2009.5420897, 2009.

Makkonen, L.: Models for the growth of rime, glaze,icicles and wet snow on structures, Philos. T. R. Soc. A, 358, 1776, 2913-2939, 2000.

Parent, O. and Ilinca, A.: Anti-icing and de-icing techniques for wind turbines: critical review, Cold regions scrience and technology, 65, 88-96, 2011.

Seifert, H., Westerhellweg, A., and Kröning, J.: Risk Analysis of Ice Throw From Wind Turbines, BOREAS VI, 9 to 11 April 2003, Pyhä, Finland, 2003.

Skamarock, W. C., J. B. Klemp, J. B., Dudhia, J., Gill, D. O., Barker, D. M., Duda, M., Huang, X.-Y., Wang, W., and Powers, 
J. G.: A Description of the Advanced Research WRF Version 3, NCAR Technical Note, 113, 2008.

Thompson, G., Rasmussen, R. M., and Manning, K.: Explicit Forecasts of Winter Precipitation Using an Improved Bulk Microphysics Scheme. Part I: Description and Sensitivity Analysis, Mon. Weather Rev., 132, 519-542, 2004.

Thompson, G., Field, P. R., Rasmussen, R. M., and Hall, W. D.: Explicit Forecasts of Winter Precipitation Using an Improved Bulk Microphysics Scheme. Part II: Implementation of a New Snow Parameterization, Mon. Weather Rev., 136, 5095-5115, 2008.
Wang, X., Bibeau, E. L., and Naterer, G.: Experimental Investigation of energy losses due to icing of a wind turbine, Challenges of Power Engineering and Environment, 14, 1143-1147, doi:10.1007/978-3-540-76694-0_212, 2007.

Westerhellweg, A. and Mönnich, K.: Prediction of Power Production Losses due to Icing based on Icing Signs in Wind Measurements, extended abstract, po140, European Wind Energy Conference and Exhibition 2010, Warsaw, Poland, 2010. 